\title{
Assessing Governments' Emergency Responses to COVID-19 Outbreak Using a Social Analysis Network (SNA)
}

\author{
Wignyo Adiyoso \\ National Development Planning Agency/BAPPENAS \\ Corresponding author: wignyoa@yahoo.com
}

\begin{abstract}
One of the effective ways to prevent spreading the COVID-19 outbreak is dependent on the non-pharmaceutical interventions due to the absence of the vaccine against the virus. This study aims to assess organizational emergency responses to COVID-19 from a social network analysis (SNA) perspective. Data were obtained from a weekly Indonesian magazine, TEMPO, which reported on the Indonesia government's response to COVID-19 from early March to early April 2020. One hundred and fifty actors represent nodes and 180 connections denotes as edges are explored and analysed using the SNA tool. The study found that the emergency response to a pandemic consisted of less solid, non-traditional structural interactions, and that the Head of the Task Force played a lesser role in the response to such an outbreak. The content analysis found that the issues of concern to team members included coordination, hoax, social distancing and the lack of testing equipment. The results of the study are expected to add literature of research on emergency response to pandemics. The findings contribute to the development of the design of organisational emergency policies in the contexts of the largescale pandemics.
\end{abstract}

Keywords: COVID-19, outbreak, government's emergency response, health crisis, social network analysis.

\section{Introduction}

Although the COVID-19 pandemic differs from natural disaster events, there are similarities (Centre for Research on the Epidemiology of Disasters - CRED, 2020; Scanlon et al., 2007). In both types of incidents, panic tends to be generated, there is a shortage of resources, including personnel, equipment and supplies, and there is a need for an emergency disaster-response approach. The World Health Organization (WHO) reported that, since the COVID-19 outbreak at the end of 2019 in Wuhan China, each country responded with different interventions, but had a crisis management framework in common (Jee, 2020; World Health Organization, 2020).

Almost all countries have established a special task force to counter coronavirus instead of using the existing emergency units in acknowledgement of the danger posed by the disease. The taskforces consist of inter-agency taskforces coordinated by a prime minister or president, a vice-prime minister or president, the Ministry of Health or health authorities. For example, in Japan, the task force is led by the prime minister in coordination with the Ministry of Health, Labour and Welfare (Ministry of Health Japan, 2020); in Australia, task forces have been led 
by the Department of Health (Australian Department of Health, 2020) while, in the Philippines, the Inter-Agency Task Force on Emerging Infectious Diseases (IATF-EID) was assigned to address COVID-19 (Department of Health, 2020). Members of the taskforce include different high-ranking officers from different ministries, such as the Ministry of Economics, the Ministry of Foreign Affairs, the Ministry of Home Affairs, the Ministry of Defence and Police, and the health research and development agencies, as well as independent experts.

It is interesting to note that, in Indonesia, the head of the special taskforce responding to COVID-19 is the Head of the National Disaster Management Agency, also known as Badan Nasional Penanggulangan Bencana (BNPB), instead of a person with a health-related background. With regard to health emergencies, Law No. 12/2018 refers to health quarantine, while disaster management, including emergency disaster response, is regulated by Law No. 24/2007 concerning Disaster Mitigation. It is worth noting that, under Disaster Mitigation Law, the definition of disaster covers natural disasters, social riots, pandemics and technological accidents (BNPB, 2020b). Although national and local contingency planning guidelines are in place in Indonesia, there is a question of inapplicability because such guidelines are focused on natural disasters instead of non-natural disasters. Although Indonesia has been admired as an example of stable post-authoritarian politics, its democratisation is not advancing (Mietzner, 2012). There has been extensive friction between the central and local governments concerning many areas related to public management issues (Rosser et al., 2011), including natural disasters and pandemics.

While studies assessing the effectiveness of the organisational responses to emergencies has attracted the attention of the field of natural and disease disaster management, little has been done to address the roles of inter-agency government departments and their networking during a large pandemic such as COVID-19. A team of emergency responders established to address such a dangerous event often consists of different organisations and people from backgrounds who do not know each other (Mohammadfam et al., 2015). As the success of outbreak prevention depends on the task force team assigned to mitigate COVID-19(Harapan et al., 2020), it is crucial to explore the roles of and dynamic relationships amongst various members of a task force working under pressure. This study aims to examine organisational government responses to COVID-19 in Indonesia from an SNA perspective. Data were obtained from a weekly Indonesian magazine, TEMPO, which reported on the government's response to COVID-19 from early March to early April 2020. The results of the study are expected to fill the gap in the research on emergency response networks, both with regard to natural disasters and emergencies due to pandemics. This study can assist decision makers and practitioners to design and manage cooperation amongst actors and their networks in future emergency response systems.

\section{Government Measures in response to COVID-19}

The Indonesian government has taken various actions in response to COVID-19. Despite public criticism concerning incapability, the government has established emergency taskforce responses to COVID-19, such as policies and regulations, large-scale social restrictions, the closure of schools, restrictions on public transport, work-from-home policies, expanded test centres, additional emergency hospitals, and social protection for the poor (EKONID, 2020) (Indonesian Ministry of Foreign Affairs, 2020). By the end of April, Indonesia was the worstaffected country in Southeast Asia and had the highest COVID-19 mortality rate in Asia at approximately 8-9 per cent (Wahyuni, 2020). On the $9^{\text {th }}$ of May 2020, the global death toll due to COVID-19 had reached 259,474, with 3, 759, 967 confirmed cases (WHO, 2020). Indonesia had 13,112 confirmed cases, with 943 deaths and 2,494 recoveries (BNPB, 2020a). 
In terms of policies and regulations, before President Joko Widodo announced the first of the infected cases on the $3^{\text {rd }}$ of March 2020, BNPB had declared (Regulation No. 7a/2020) a "particular state" of disaster emergency in anticipation of the COVID-19 pandemic from the $28^{\text {th }}$ of January 2020 to the $28^{\text {th }}$ of February 2020. This regulation was later revised (Regulation No. 9a/2020) to extend the duration of the disaster emergency until the $30^{\text {th }}$ of May 2020 . The declaration alerted the public to the immediate shift to an emergency situation. BNPB became the leading agency responsible for evacuating Indonesia citizens living in Wuhan, China, and brought them back to the military-based Natuna Island for isolation. Other regulations include Presidential Regulation No. 11/2020 on Public Health Emergency Declaration and Presidential Regulation No. 12/2020 on COVID-19 Pandemic as National Disaster (issued on the $13^{\text {th }}$ of April 2020).

A significant regulation to address the organisational emergency response to the COVID19 outbreak was Presidential Decree No. 7/2020 (Keppres No. 7/2020) concerning the Mitigation Task Force, which was issued on the $13^{\text {th }}$ of March 2020. The task force consists of the Steering Committee (SC) and the Executive Taskforce. It is important to note that the president appointed the head of BNPB as Chief of Mitigation Taskforce Response to COVID19 instead of the Minister of Health $(\mathrm{MoH})$. The MoH serves as a Vice-Head of the SC led by the Minister of Human and Culture Development (MoHCD) as the head of the SC.

The members of the task force are high-ranking officers and staff from the BNPB, the MoH, the Ministry of State-owned Enterprise (MoSE), the Ministry of Transportation (MoT), the Ministry of Politics and Security (MoPS), the Ministry of Economic Coordination Affairs (MoECA) and other related ministries, universities, research institutes and personnel from a public hospital. In terms of structural organisation, the Presidential Decree on taskforces did not specify divisions or sub-divisions. On the $24^{\text {th }}$ of March 2020, the decree was revised via Presidential Decree No. 9/2020 (Keppres No. 9/2020), with the Minister of Finance (MoF) being appointed as secretary and new members being added to the taskforce (ANTARA, 2020) (EKONID, 2020). In terms of crisis communication, before the mitigation taskforce response was established, the government also assigned high officials from the $\mathrm{MoH}$ to serve as spokespersons for the Mitigation Taskforce team.

In terms of economic impact, some government regulations, such as Law No. 1/2020 (Perppu No. 1/2020) on State Finance Policy and Financial System Stability in addressing COVID-19 (EKONID, 2020) have been issued. The government has also pledged a budget of approximately 405.1 trillion Rupiah (equivalent to about 24.7 billion USD) to combat the COVID-19 pandemic. Other regulations are Presidential Instruction (in press) No.4/2020 on Refocusing the budget on healthcare, the disbursement of social funds and economic stimulus. There are also other regulations that apply to industry, taxes, small-to-medium enterprises and export-import policies.

Disagreements between the central government and provincial governments concerning lockdowns or social distancing policies have caused tension. The central government prefers to apply social distancing instead of lockdown policies. Due to escalating cases in surrounding Jakarta Greater City (Bekasi, Bogor and Depok cities), the governor of Jakarta insisted that the central government should allow the application of partial lockdown policies in Jakarta. The public also called for the central government to be stricter rather than relying on social distancing. Finally, on the $4^{\text {th }}$ of April 2020, the MoH issued Regulation No. 9/2020 on Guidelines to Large-Scale Social Restriction (Pembatasan Sosial Berskala Besar or PSBB). Not only has there been public criticism of the partial lockdown, but several issues, such as the shortage of masks and hand sanitisers, insufficient rapid tests and personnel protection for medical workers, the lack of health facilities, and the lack of coordination amongst government offices have also been raised (Djalante et al., 2020). Other crucial issues are lack of transparent 
data, the lack of centres and facilities for rapid testing, inconsistent policies concerning public transport and the urgent need for a social safety net for the poor.

\section{Theoretical framework}

The study of emergency responses is largely recognised as being important from academic and practical perspectives. Countless studies of emergency responses to natural disasters, manmade disasters and public health pandemics have focused on organisational performance (Houghton et al., 2006), communication (Creswick et al., 2009) and community response (Kim et al., 2014); however, studies investigating the roles of members of emergency teams and their networks during a crisis caused by a pandemic is limited. It is widely acknowledged that human factors play important roles in determining the effectiveness of organisations (Van der Hulst, 2009).

Although organisational theories have provided principles, standards, guidelines and rules, as well as systematic explanations concerning how individuals and groups shape an organisation, institutions have different characteristics during times of peace and in crisis situations. It has been argued that effectiveness of emergency response organisations, which is characterised as a complex response to sudden changes, often depends on the roles that members play and the ways in which they interact and communicate in a calamitous crisis situation. In addition, the importance of utilising a social network approach in social studies, including disasters and pandemic outbreaks, is widely known (Magsino, 2009). A social network is a useful tool to analyse the role of an organisation or of group members and their relationship patterns in order to understand how an emergency response team functions in a crisis.

An emergency response is one of the functions of disaster management cycles, which consist of four functions or phases, namely mitigation, preparedness, emergency response and recovery. While there is no single definition of an emergency response, the general features of emergency responses include quick actions, planning and operations, rescue, leadership, command systems, coordination, communication, logistics and inter-agencies cooperation (Drabek, 2005) (Lurie et al., 2013). Emergency response management will be effective under specific conditions, such as adequate planning, having an incident command system, appropriate communication and coordination, available equipment, and effective drills and training (Bennett, 2011). Similar to WHO, the critical functions of incident management systems consist of direction or leadership, coordination, communication and planning, operations and technical expertise, support and logistics, and finance and administration (WHO, 2019).

A large emergency management team consists of several members with a variety of backgrounds and experience led by a manager. The emergency response manager is responsible for strategic direction and daily operations, as well as for surveillance and response to the emergency events. He/she has full authority to delegate and assign critical functions and should work with other organisations based on the strategic plan and priorities (WHO, 2019). Under the top leader of an organisation are the secretary, the head of divisions or sub-divisions, and other ad-hoc teams that operate based on planning and operational strategies, the command system, standard operating procedures and other guidelines. Each division requires specific knowledge and expertise; therefore team members often have from different backgrounds and come from different organisations. It is widely known that an emergency response system consists not only of governmental bodies, but also parties such as general communities, religious communities, private organisations, the media and other non-government 
organisations (Uhr \& Johansson, 2007), including non-institutional actors (Giordano et al., 2017).

Coordination (and planning) is one of the most important aspects of emergency response. Planning and coordination with different authorities and levels of organisations is indispensable in emergency response management (Raju \& Van Niekerk, 2013). A pandemic such as COVID-19 is a complex, vast and invisible threat that requires the involvement of many different jurisdictions, diverse expertise, and different levels within governments to avoid overlaps due to policies and regulations. Coordination in emergency response teams is critical, and can include effective preparation, and a better understanding of the roles, responsibilities and authority of members, which allows for the scheduling of functions and ensuring that organisational activities are appropriate (Mohammadfam et al., 2015). Effective coordination improves communication, reciprocal cooperation, and avoids duplication and misunderstandings within the organisational team. There are at least three types of coordination, including micro, intermediate and macro coordination (Bharosa et al., 2010). While the macro-perspective of coordination involves wide inter-organisational activity, the intermediate and micro-perspectives focus on within organisations and amongst people, respectively.

One way to improve coordination and operational problems in organisational responses to disasters is to develop a system for emergency responses, such as an incident command system (ICS), an Incident Management System (IMS) or a National Incident Management System (NIMS) (Lindell et al., 2005). These systems can improve coordination by applying standardised organisational plans, structures and emergency response training. In the United States, the NIMS model has been used frequently by most emergency management across all levels of government as this model offers a framework for improved coordination in a crisis and provides access to the resources needed to support an effective emergency response (Annelli, 2006). It is also worth noting that an ICS should be based in a designated operation centre (WHO, 2013). Providing a dedicated situation room can ensure systematic coordination of information, human resources, logistics, administration and facilities to support decision making and implementation during a crisis.

Another important feature of an emergency response is communication. Although the effectiveness of risk communication has been demonstrated in many research publications, policies, and guidelines for disaster and public health interventions, many crisis organisations have failed to adopt such an approach to communication (Vasterman \& Ruigrok, 2013). The government media often fails to channel information about risks to the public (Silva et al., 2019).

Issues related to communication in disaster and pandemic crises include not only how organisations can delivers information better, but also the fact that risk communication is different during a crisis (Longstaff \& Yang, 2008) (Vaughan \& Tinker, 2009). People experiencing threats such as disease are influenced by complex aspects such as demographics, the perceived likelihood of the risk, the experience of disaster, religion and other social and cultural aspects (Wachinger et al., 2013) (Adiyoso \& Kanegae, 2013). Another factor in risk communication is that managers should respond immediately to a pandemic instead of delaying decisions due to a need for discussions or to receive feedback (Holmes, 2008). Moreover, many studies have reported that trust is key to effective communication and relationships (Vedula et al., 2017) (Xu \& Zhao, 2011). Trust affects openness, removes barriers and allows for the clear communication that is required in an organisation addressing such a crisis.

Studies of disaster management and public health using SNA have focused extensively on the use of social media or media coverage during disasters and pandemics (Yeo et al., 2018) 
(Vasterman \& Ruigrok, 2013) Reintjes et al. 2016; Nerlich and Halliday 2007; Lee and Basnyat 2013). SNA has also been employed to examine the role of non-profit organisations during a disaster (Kapucu et al., 2011) (Olanrewaju \& Ahmad, 2018) (Bisri, 2013), as well as the resilience of community networks (Magsino, 2009) (Franco et al., 2013) and public response post-disaster (Chatfield \& Brajawidagda, 2012). However, research assessing the comprehensive roles of members and their relationships in inter-ministerial agencies in the context of a large and rapid global pandemic is limited. The studies that do exist have focused only on communication, relationships and trust in emergency response teams (Patterson et al., 2013) and the performance of the spokesperson in terms of communicating risk (Lyu et al., 2013).

SNA provides a useful tool for describing and understanding complex structures and their relationships in a group or organisation. Network analysis can identify which members play central roles in an organisation, the closeness or distance of members and the features of individuals' relationships. Network analysis allows policymakers to prepare the most effective interventions and to prevent the failure of emergency organisations in response to a disaster such as the terrorist attack on September 11, 2001. In his study, Kapucu (2005) analysed patterns of communication and information flows amongst actors in Federal Emergency Management Agency (FEMA) after a terrorist attack, and revealed that there was a gap between actual performance and designated roles in the Federal Response Plan. Network analysis approach is capable of explaining the configuration of the different actors and their links that are not observable by the public.

The SNA is the study of interrelated human systems through the assessment and characterisation of actors and their relationships in a set of group systems. According to Borgatti (Borgatti \& Li, 2009), actors can be people, groups, firms, organisations or countries, and their roles can encompass an entire network, while relationships or links may be associated with kinship, authority and power, communication, friendship, sentiment or feeling (Borgatti $\&$ Ofem, 2010). One actor may have more relationships than others, while some may have few connections. The more links actors have, the more popularity or power they may have, and they may have more resources. The relationships amongst actors may be strong or weak, while connections may be close or at a distance. The networks that have weak ties may show a slow response. In contrast, networks are stronger ties and have shorth paths may be more quick to respond (Kapucu, 2015). A study that used a social network-based coordination model involving 224 participants found that there was a link between network ties and coordinated emergency response networks (Hossain \& Kuti, 2010).

Advanced in algorithm and graph visualisation on computer-based applications supporting SNA has helped researchers, policymakers and others to understand the complexity and interactions of individuals in any organisation or group. Software such as Ucinet, NodeXl, NetDraw, E-Net, KeyPlayer, StOCNET, Automap, Pajek and Gephi has been developed and can process and present data networks visually (Apostolato, 2015). Gephi provides a statistics and metrics framework, thus allowing it to analyse social network features such as degree centrality, 'betweenness' and closeness centrality, diameters, coefficients, short paths, pageranks, and ego networks or modularity. Another useful feature of Gephi is that it is equipped with excellent and rich visualisation features obtain via exploration of large networks (Jacomy et al., 2014).

\section{Methods}

\section{Participants}

SNA pertains to the roles of actors or people and their relationships with others in a group. When collecting data, identifying the actors or people involved in the mitigation taskforce 
team's response to COVID-19 and the relationships among them is of paramount importance. All the data were obtained from six issues of the weekly Indonesian magazine, TEMPO, following the method used to study the presidential candidacy during Indonesia's general election in 2014 (Eriyanto, 2014). TEMPO is one of the respected and independent weekly magazines in Indonesia. Another reason for using TEMPO was the impossibility of accessing the actors involved in the Mitigation Task Force, who are mainly high-ranking government officers. Secondly, it was difficult to contact the task force members and other people involved in the response to COVID-19 due to the large-scale restrictions. Thirdly, TEMPO covered the progress of the government's response to COVID-19 from early March to early April 2020 by publishing four special issues reporting on COVID-19 and by reporting news about COVID19 in two other issues (Tempo, 2020).

\section{Measures}

The people or actors identified were mainly government officers involved in contributing to the formulation and execution of the emergency response to COVID-19. They were either official members of a task force or had other roles and positions that linked them directly or indirectly to the task force members. However, in a few cases, people who were not involved in the response team were included because they had links to taskforce members, such as a person suspected of being infected, local health workers, independent experts and nongovernment organisations (NGOs), who often respond to government policies regarding COVID-19.

Relationships or ties amongst taskforce members were classified based on whether they involved direct meetings, assignments, a hierarchy of instructions, on-line meetings, responding, communicating, mentioning, and referencing. For example, when the president spoke in public and addressed such issues in a speech asking the MoF to relocate the budget for the fight against COVID-19, this was categorised as one relationship between the president and the MoF. As such relationships are complicated, the relationships amongst people in the taskforce team are considered indirect relationships, and weighting was not applied. The data gathered identified more than 180 relationships or ties. This study also used the content analysis method to identify the important themes or topics being discussed, communicated, or responded to by the parties. For example, when the president instructed the $\mathrm{MoH}$ to prepare more rapid tests for COVID-19, the shortage of rapid tests was categorised as a topic discussed by or concerning both the president and the $\mathrm{MoH}$

\section{Analysis}

The analysis of the network attributes was conducted using Gephi Version 9.1.2 and applying calculations of density, degree of centrality, closeness and betweenness centrality and modularity (egocentric networks). Density corresponded to all the members focused, while tied related to the connectedness amongst them (Thangaraj \& Amutha, 2018). The density is represented by scores from $0-1$ (Eriyanto, 2014). The higher the number, the denser the network. Degree centrality explains who had the most connections, while closeness centrality refers to how close an actor was to others, and betweenness centrality is related to the roles of actor to connect one sub-group to another. Centralities are measured using a particular score and often use normalised data. The normalised scores were from $0-1$. The higher the score, the greater the degree of the actor's closeness and betweenness centrality. Modularity, or egocentric networks, explains the degree of separation. 


\section{Results}

One hundred and fifty nodes or actors were identified as being reported in TEMPO, including President, the MoH, the MoHCD, the Head of the Taskforce, MoFA, the MoF, the MoSE, six governors of Java Island, the head of the Local Government Health Office, the Director General of $\mathrm{MoH}$, and the Minister of Industry, special staff of $\mathrm{MoH}$ and MoSE, the spokesperson for the taskforce, researchers, professors, and public health associations and NGOs.

In terms of relationships or edges, an analysis of the data obtained from TEMPO revealed that there were more than 180 relationships or ties amongst the people involved in responding to COVID-19. Various relationships, such as direct meetings, instructions, communication, online meetings, responses, answers, lobbying, sending letters and other interactions were identified. A frequent relationship was direct meetings between the president and ministers, and the chief of the taskforce or ministers with other ministers or governors. Another form of tie was that relationship between the governor of Jakarta and ministers when discussing whether Jakarta City should be placed in partial lockdown or not. For example, TEMPO reported that the governor of Jakarta sent a letter requesting social restriction to the MoPS. Different people have many relationships depending on their role(s) in a team. For example, the spokesperson for the task force had different kinds of ties because he had to respond to many actors via various actions. He sometimes responded to the criticism from the public, or to elaborate on strategic government policies.

Overall, the density of the 150 actors involved in the government task force responding to COVID-19 was 0.016 , which is very low. This indicates that not all the actors were connected proportionally. Density is used to explain how all the actors interact with each other. The perfect density parameter is 1 , as this is the score indicating that all the actors had relationships or contact with each other. The limited network was also reflected in the diameter network, which was 13 . This means that the farthest distance from one actor to others was approximately 13 paths. In addition, the average distance to each actor in the network was around 4.4 paths. The distance illustrates the degree to which the network is interrelated. A solid network indicates how close each person is to others in terms of contact or communication without third parties being involved. As there were actors at an average distance of 4.4, this shows that more than five people were required in order for an actor to contact others. Figure 1 shows that the visualised network is less dense and centring on a few actors. The $\mathrm{MoH}$, the president, the spokesperson for the taskforce, the chief of the taskforce, the governor of Jakarta, the MoSE and the MoHCD were amongst the actors at the centre. The scattered nodes at the top right show that they only had connections to a limited number of other members. 


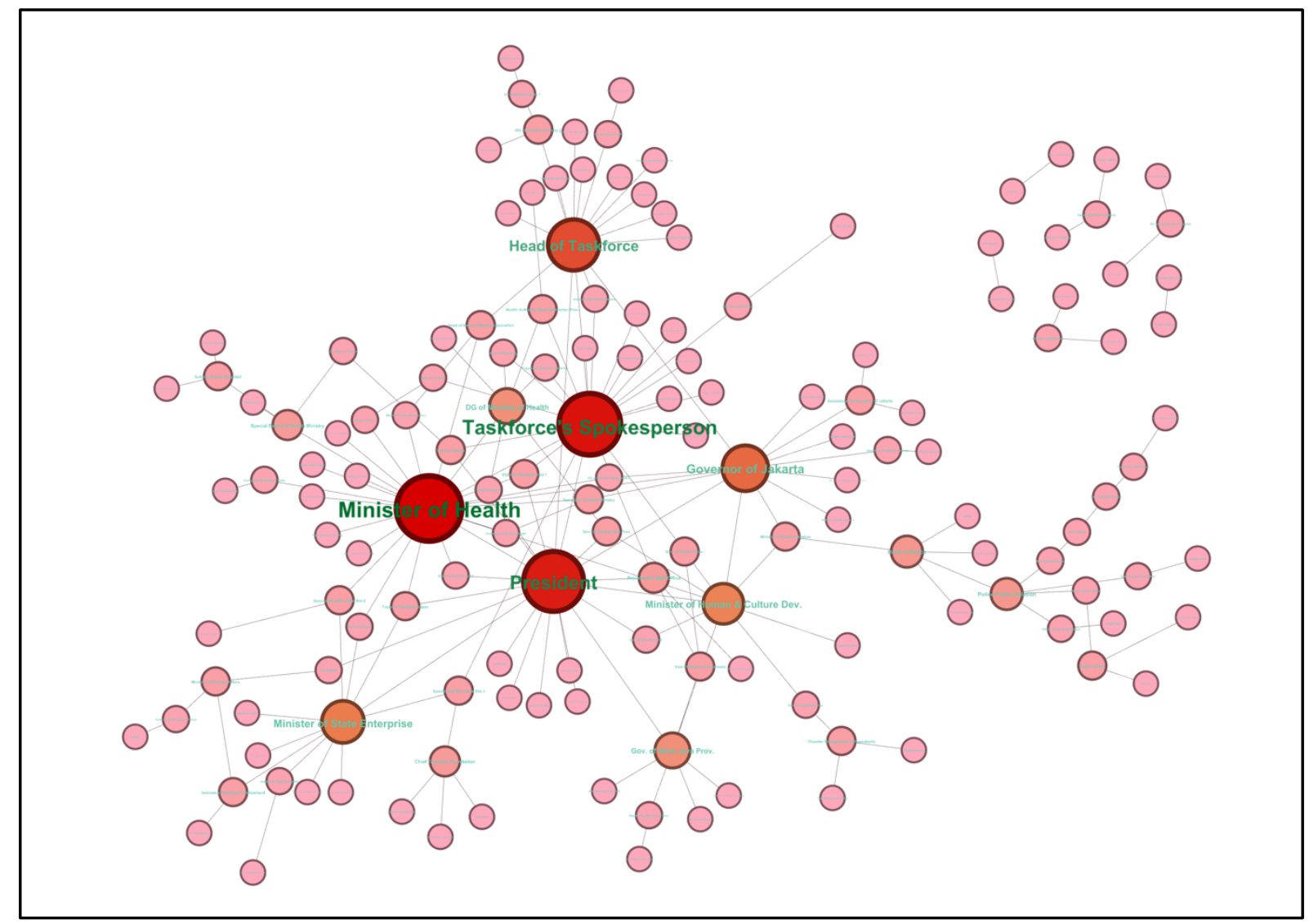

Fig. 1. The Network of the Taskforce Response to COVID-19

In terms of the roles of actors in the network, Table 1 show the degree of centrality of the top 10 actors, in which the president and the MoH were the most strongly connected actors. The third and fourth actors were the chief of the taskforce and the spokesperson for the taskforce, respectively. It is interesting to note that the governor of Jakarta was the fifth most closely linked actor. Other members with more connections were the MoSE, the MoHCD, director general of the $\mathrm{MoH}$, the governor of West Java Province and police public relation officers. Degree centrality indicates that the most extensively connected actors may have more power and be more active, more responsible and more popular compared to others. 
Table 1. Degree Centrality

\begin{tabular}{lc}
\hline \multicolumn{1}{c}{ Actors } & $\begin{array}{c}\text { Degree } \\
\text { Centrality }\end{array}$ \\
\hline Minister of Health & 24 \\
Taskforce's Spokesperson & 22 \\
President & 21 \\
Head of Taskforce & 16 \\
Governor of Jakarta & 13 \\
Minister of State Enterprise & 11 \\
Minister of Human \& Culture Dev. & 10 \\
DG of Ministry of Health & 7 \\
Gov. of West Java Prov. & 7 \\
Police Public Relation & 5 \\
\hline
\end{tabular}

Table 2 shows the statistical results for the closeness and betweenness centrality of the network. Closeness centrality refers to how close an actor is to other actors in the group. It shows the average path from the first node to all the nodes in the network. The higher the normalised score of closeness centrality, the closer the network. Table 2 shows that the top ten actors with the closest networks were the special staff for the president, the Minister of Manpower (MoMP), the Director of Central Java Hospital, immigration officers, Immigration Office in West Nusa Tenggara (NTB), the MoD, the airport authority, the Indonesian military, health quarantine in NTB and WHO Indonesia.

Table 2. Closeness and Betweenness Centrality

\begin{tabular}{lclc}
\hline \multicolumn{1}{c}{ Actors } & $\begin{array}{c}\text { Closeness } \\
\text { Centrality }\end{array}$ & \multicolumn{1}{c}{ Actors } & $\begin{array}{c}\text { Betweenness } \\
\text { Centrality }\end{array}$ \\
\hline Special Staff for the President & 1 & President & 0.2887 \\
Minister of Manpower & 1 & Minister of Health & 0.2560 \\
Dir. of Central Java Hospital & 1 & Taskforce's Spokesperson & 0.2212 \\
Immigration & 1 & Governor of Jakarta & 0.2159 \\
NTB Immigration & 1 & Minister of Com \& & 0.1893 \\
Minister of Defence & 1 & Information & 0.1888 \\
Airport Authority & 1 & Head of Taskforce & 0.1844 \\
Indonesia's Military Chief & 1 & Minister of Human \& & 0.1545 \\
Health Quarantine in Mataram & 1 & Culture Dev. & 0.1481 \\
WHO Indonesia & 0.2827 & Minister of State Enterprise & 0.1081 \\
\hline
\end{tabular}


In addition, Table 2 shows the betweenness centrality results for the top ten actors in the network. The higher the score, the greater the actor's role as a connector to other sub-group networks. The president was the top actor in the betweenness centrality amongst other members. The lower ratings were for the $\mathrm{MoH}$, the spokesperson for the taskforce, the governor of Jakarta, the Ministry of Communication and Information (MoCI) and the head of the taskforce, respectively. The remaining actors with high betweenness centrality were the Head of Police, the MoHCD, police public relation officers and the MoSE.

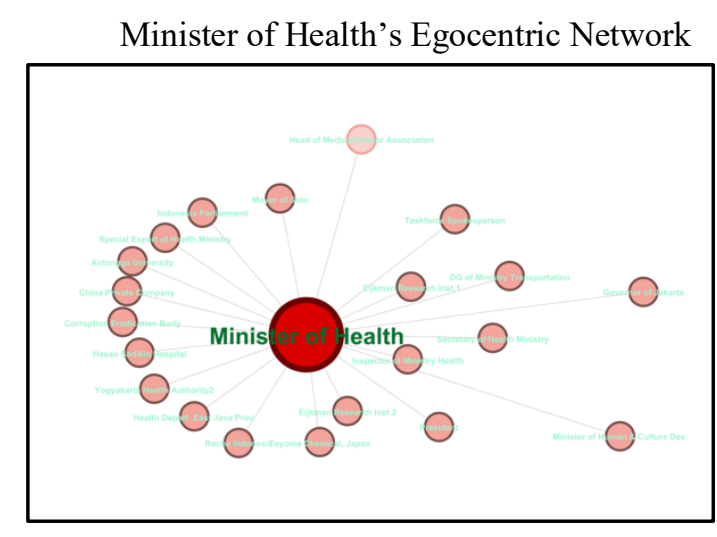

Taskforce's Spokesperson's Egocentric

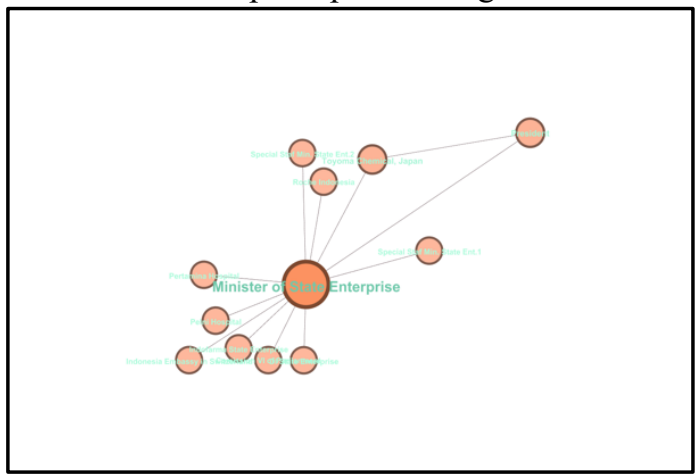

Governor of Jakarta's Egocentric

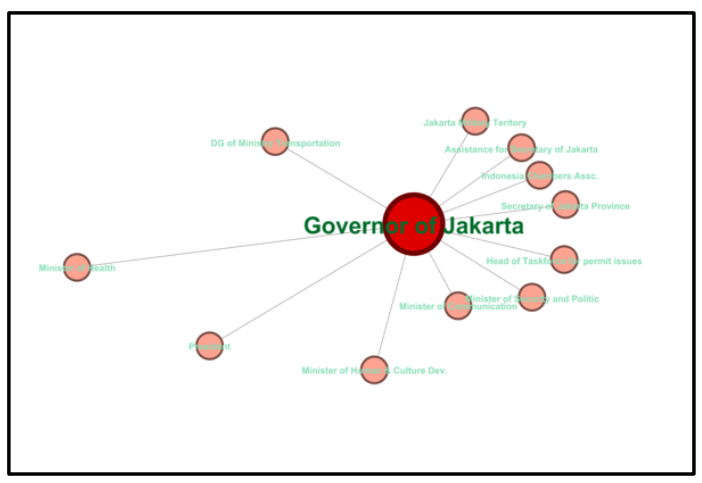

Fig. 2. The Top Six Actors of Egocentric Network
President's Egocentric Network

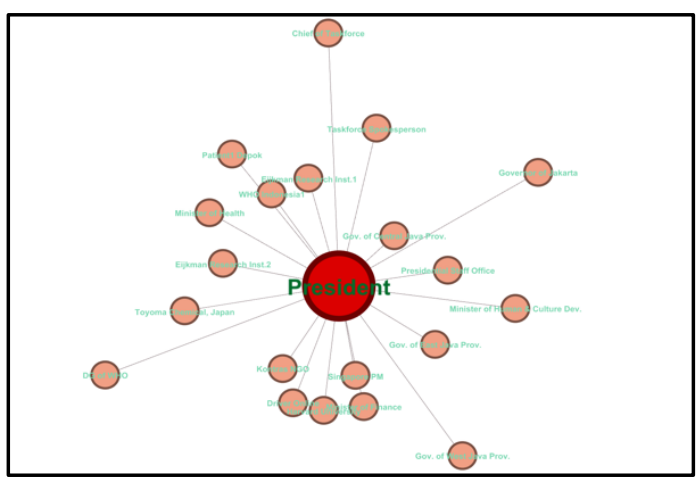

Head of Taskforce's Egocentric

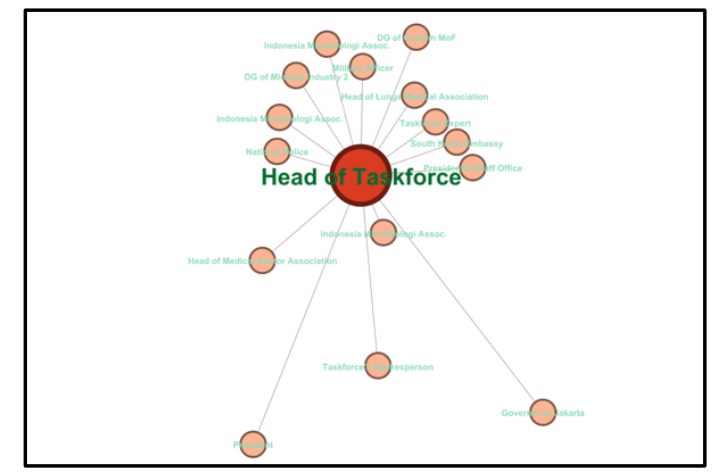

Minister of State Enterprise's Egocentric

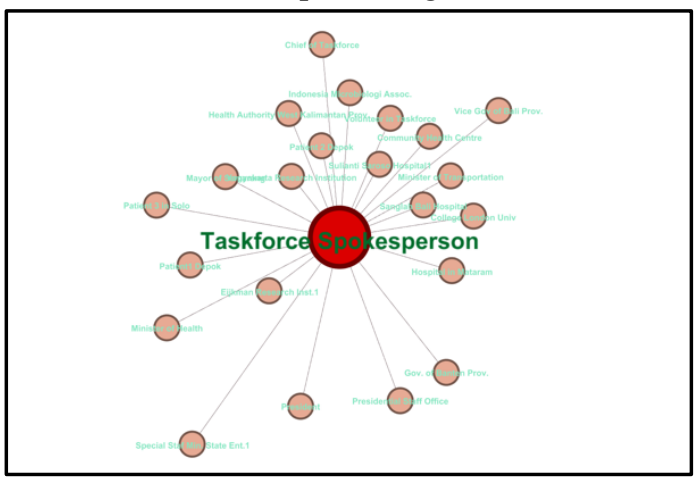

Another important aspect of network analysis is the egocentric network (Rice \& Yoshioka-Maxwell, 2015). The egocentric network refers to a sub-group network in which members are centred on one actor. A modularity analysis using Gephi resulted in 11 sub-group 
networks. Figure 2 shows the top six egocentric networks. The first was the MoH, which had ties to the president, the taskforce's spokesperson, the MoHCD and the governor of Jakarta. Most of the actors connected to him were people involved in health organisations, such as the Director General of the $\mathrm{MoH}$, Inspector of the $\mathrm{MoH}$ and special staff of the $\mathrm{MoH}$ and public hospitals. Apart from these actors, he also had relationships with the Corruption Eradication Body, Roche Indonesia, Toyoma Chemical and the Eijkman Institute.

The second actor in the egocentric network is the president's sub-network, which is mainly connected to actors who have other actors with degree centrality, such as the $\mathrm{MoH}$, the taskforce's spokesperson, the head of the taskforce, the governor of Jakarta, the MoSE and the MoHCD. Other actors connected to the president are the Minister of Defence, the Minister of Manpower, some governors, special staff of the president, WHO Indonesia, the Eijkman Research Institute and Toyoma Chemical.

The taskforce's spokesperson is another egocentric network. As the spokesperson appears on television almost every day to communicate information about, announce and respond to issues related to COVID-19 to the public, he has contact with the president, the MoH, the chief of the taskforce and local governments. The spokesperson has also connections to various actors outside of government officers such as patients, public health associations, research institutes and NGOs. The chief of the taskforce has relationships with the president, the $\mathrm{MoH}$, the taskforce's spokesperson, the police, the military, experts, volunteers and medical doctor associations. Surprisingly, he has no relationship with the Head of SC of the Taskforce. Other connections are with the South Korean Embassy in Jakarta and with University Islam Malaysia.

The governor of Jakarta and the MoSE constitute the rest of the top six sub-groups of networks. The governor has relationships with the president, the MoH, the MoHCD, the MoPS, the MoIC and internal staff in Jakarta Province. Of interest, the MoSE only has a relationship with the president and mainly coordinates with his staff, including special staff and the Director of State Companies. The MoSE manages vital state-owned companies such as oil and gas, electricity, medical and health industries, foods, infrastructure and others.

The findings also revealed the issues or topics of concern to the actors in the network. Figure 3 shows the number of issues that appeared in the network. The most common issues were coordination, hoax issues, social distancing, the availability of testing equipment and facilities for rapid testing. Other themes were the shortage of protective medical equipment, chloroquine usage, and hierarchy connections. The president praised some governors for their preparation, the announcement of new cases, obtaining rapid testing equipment and good handling of cases, while limited testing centres was amongst the topics receiving the attention of members of the group. 


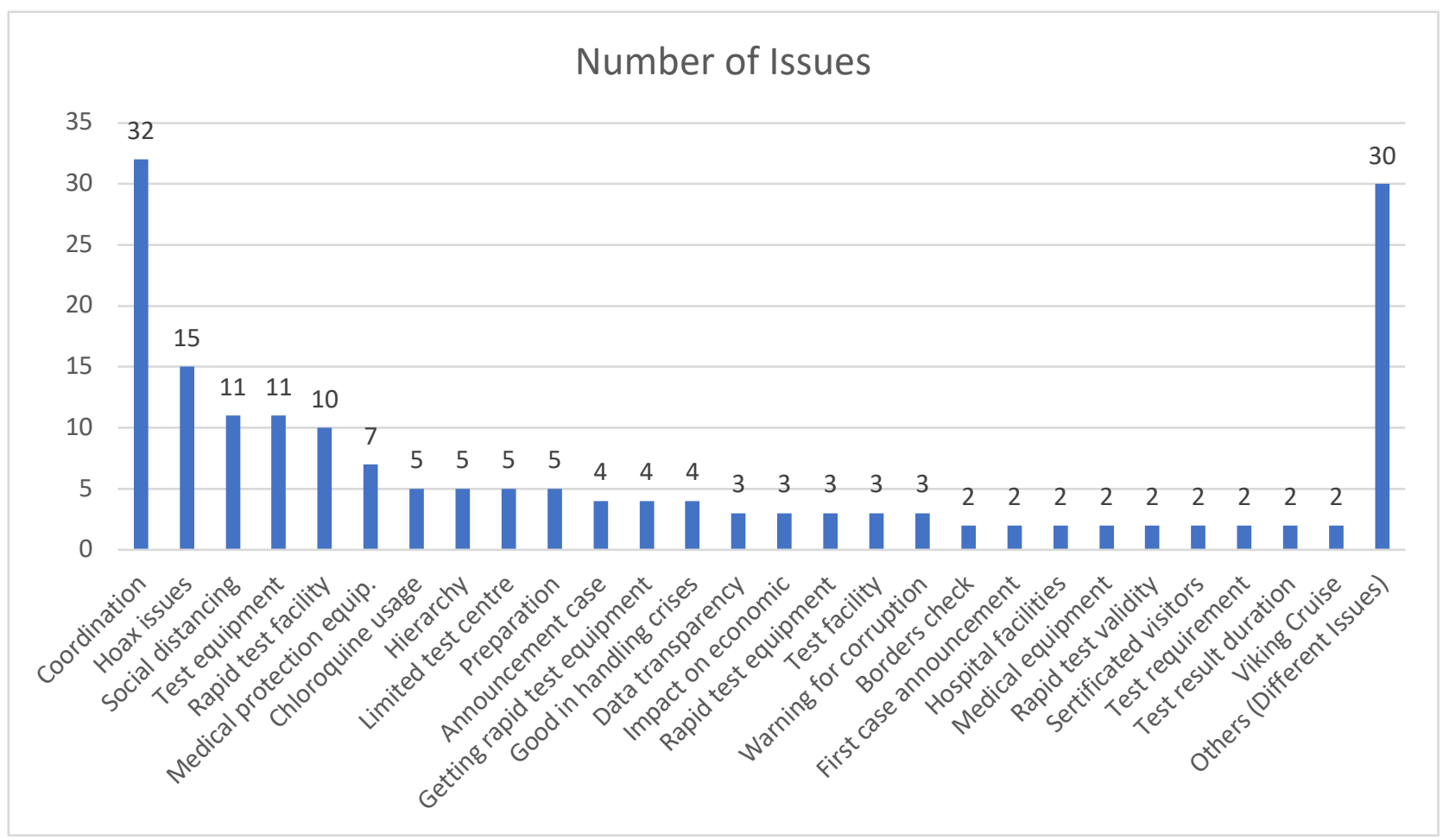

Fig. 3. Number Issues Concerning the Taskforce Response Team to COVID-19

\section{Discussions}

The network of organisational government in response to COVID-19 was represented by a low-density visualisation, which shows that members of the taskforce were less connected to others. Each member tended to be linked to a particular person in the group. In addition, the connections amongst individuals was unsystematic. The pattern also shows that the role of the chief of the task force was not at the centre of the group, indicating that the hierarchical structure does not work effectively. This finding is in line with (Cross et al., 2002) study in collaboration with a consortium of Fortune 500 companies involving twenty-two different organisations, which revealed that the traditional hierarchy of functional structures was less effective than were informal relationships. This study found that social networks were more able to increase collective knowledge, assess different collaborations and ensure integration when restructuring an organisation than were formal structures (Cross et al., 2002).

In terms of actors' centrality, it is clear that the head of the taskforce is not the epicentre of the group. As commander of the incident system, he has fewer connections than do the president, the $\mathrm{MoH}$ and the taskforce's spokesperson. According to network analysis, the actor with the greatest degree of centrality may be the most popular or important person in the network. With regard to a large and critical COVID-19 outbreak, it is reasonable to assume that the president would be the person most involved in response activities. During a pandemic, the president needs to address various directions and issues concerning the disease. Similarly, the taskforce's spokesperson disseminates information about COVID-19 to the public, and appears daily to announce, address and respond to any issues related to the progress of the response to COVID-19. However, it is worth noting that the strong leadership of the taskforce 
is critical in reducing the spread of coronavirus as demonstrated in Wuhan, China (Forman et al., 2020).

It was surprising that the $\mathrm{MoH}$ always ranked higher in centrality than did the chief of the taskforce and the MoHCD as the head of the SC of the taskforce. Even in terms of betweenness centrality, apart from the president, the $\mathrm{MoH}$, the taskforce's spokesperson, the governor of Jakarta and the MoCI played more roles than did the head of the taskforce and the head of the SC. The domination of the MoH in the network might be because COVID-19 is perceived as the MoH's responsibility. Another possible reason is that many organisations related to public health that are tackling COVID-19 are under the authority of the MoH, such as public hospitals (on both the central and local levels), health research institutes, rapid testing facilities and the medical procurement authority. This result of this study support that previous research exploring the Missouri's System of Public Health Emergency Planners, in which most planners interacted regularly with planners in their region but seldom with planners outside their region (Harris \& Clements, 2007). This imply that members of taskforce coming from $\mathrm{MoH}$ tended to communicate with their colleagues in $\mathrm{MoH}$ organization or related to the health authorities.

The appearance of the governor of Jakarta in the network of governmental responses to COVID-19 is not surprising. Jakarta was hit hardest by the outbreak. As the capital city and because it is a national and international hub, Jakarta is extremely vulnerable to the coronavirus. The governor took active measures to prepare for and to address the outbreak. He preferred lockdown policies other than the partial lockdown proposed by the central government. In terms of funding, Jakarta has a significant amount of money compared to other provincial governments, although decisions such as lockdown policies remain under the authority of the central government. Different organisational authorities are involved in responding to a crisis, which affects the effectiveness of emergency response organisations. The finding is similar to previous study on social support for prenatal health found that the smaller network, in terms of number of members, was the more active network (Hether et al., 2016). Another possible reason is that each organisation has different laws and regulations and are often in conflict with each other therefore the governor might prefer to work with internal Jakarta province instead of the larger stakeholders.

Another active involvement is MoSE. The reason may be that the MoSE has economic resources to support the taskforce in relation to the building of health facilities, the purchasing of rapid tests and other forms of support that are not required bureaucratic procedures. However, it is interesting to analyse why other ministries are more active than is the chief of the taskforce, who is also the Head of the BNPB. Under the hierarchical government system, the BNPB is at a lower level than are the ministries, although it is directly under the president. This is not surprising due to the political culture of Indonesia. Social culture is still dominant in the Indonesian political system, and the result is that those in higher-level positions are reluctant to be given instruction by those in lower-level positions (Pratama, 2017).

Another explanation for the low function of the chief of the taskforce is the overlapping of regulations. Law No. 24/2007 states that disasters include natural and non-natural disasters such as a pandemics, technological accidents and social riots. In addition, Presidential Regulation No. 17/2018 gives the BNPB the authority to take action during disasters in a certain situation. By contrast, Law No.36/2009 and Law No. 6/2028 on Health and Health Quarantine grant the $\mathrm{MoH}$ control of the pandemic on behalf of the central government. These complicated laws and diverse organisations may contribute to the relationships of the members in the taskforce responding to COVID-19 forming a fairly uneven network.

Other interesting findings were that major issues embedded in the relationships of the network were coordination, hoax issues and social distancing. Concern that the main problem 
in managing an emergency response was coordination was widespread. Coordination involves the entire group of members, including divisions or sub-divisions, as well as amongst task force members, other government institutions and wider communities. Integrating different resources and different functions in a panic situation and taking urgent action during a largescale pandemic across the nation is a challenge for emergency response managers. The problem of coordination also related to the communication of risk. Communication of risk during a crisis is often difficult, as supported by the crisis literature, which notes that hoaxes and fake news become serious problems during a crisis (Sellnow et al., 2019). It is recommended that emergency managers focus on real issues rather than on hoaxes and educate the public in terms of media literacy. Unfortunately, testing equipment, rapid testing facilities and protective medical equipment are seen as second priorities to be addressed by the taskforce responding to COVID-19. Similar to the findings of Drew and his colleagues (Drew et al., 2011), this result is consistent with the result of the study on evaluation of Sexuality Policy Watch (SPW), a global forum of organizations and individuals active within the field of sexuality, found that just over one third (34\%) of individuals were considered to be focused on primary on sexual and reproductive rights topic, and almost two thirds $(63 \%)$ had either a primary or secondary focus on this topic. Such primary issues should be the priority, as a vaccine for the virus has not yet been invented; thus, non-pharmaceutical intervention, such as early detection using rapid testing, is an important measure.

\section{Conclusion}

The COVID-19 pandemic has become a disaster for humanity. The purpose of this study was to assess and explore the organisational emergency response to COVID-19 from the SNA perspective. The data analysed were obtained from a weekly magazine that reported on the emergency response to COVID-19 in March of 2020. This study concluded that the emergency response to the pandemic is less cohesive, indicating the roles of non-structural organisations and the limited roles of the chief of the taskforce and the head of SC in managing the emergency responses. The dynamic roles of actors and their relationships within the group reflect the weaknesses of the organisational emergency response to COVID-19. The complexity of the problems in combating COVID-19 has led to major challenges for the taskforce team. Cultural aspects, the overlapping of regulations and the lack of communication between central and local governments may have contributed to the lack of cohesion in the organisational response.

The first major issues raised by members of the task force were related to coordination, hoaxes and social distancing. Important issues such as shortages of testing equipment, protective medical equipment, and rapid testing facilities were of secondary concern in the emergency response to COVID-19. This study provides valuable insights into the dynamic roles of team members and their networks, which are crucial for the success of the response to COVID-19. The findings are expected to contribute to the development of the design of organisational emergency policies in different contexts, particularly to future disaster and emergency responses to a large-scale pandemic. The first limitation of this study is that, since the actors involved in the government's emergency response were only identified from six issues of a weekly magazine, not all of the actors' activities and relationships have been covered. Secondly, as this study was conducted in a short time, it may change the dynamics of emergency responses to COVID-19.

\section{Disclaimer}

The views and opinions expressed in this article are those of the author and do not necessarily reflect the official policy or position of author's agency. 


\section{Declaration of Conflicting of interest}

The author declared no potential conflicts of interest with respect to the research, authorship, and/or publication of this article.

\section{Funding}

The author received no financial support for the research and or authorship of this article.

\section{References}

Adiyoso, W., \& Kanegae, H. (2013). Effectiveness of disaster-based school program on students' earthquake-preparedness. Journal of Disaster Research, 8(5), 1009-1017. https://doi.org/10.20965/jdr.2013.p1009

Annelli, J. F. (2006). The National Incident Management System: A multi-agency approach to emergency response in the United States of America. OIE Revue Scientifique et Technique, 25(1), 223-231. https://doi.org/10.20506/rst.25.1.1656

ANTARA. (2020). Law Enforcement Key to Handling COVID-19: BNPB. https://en.antaranews.com/news/144514/law-enforcement-key-to-handling-covid-19bnpb

Apostolato, I.-A. (2015). An overview of Software Applications for Social Network Analysis. International Review of Social Research, 3(3), 71-77. https://doi.org/10.1515/irsr-2013-0023

Australian Department of Health. (2020). Government response to the COVID-19 outbreak. https://www.health.gov.au/news/health-alerts/novel-coronavirus-2019-ncov-healthalert/government-response-to-the-covid-19-outbreak

Bennett, B. (2011). Effective Emergency Management. Professional Safety, November, 2837. https://www.ahimta.org/resources/Documents/EffectiveEmergency.pdf

Bharosa, N., Lee, J., \& Janssen, M. (2010). Challenges and obstacles in sharing and coordinating information during multi-agency disaster response: Propositions from field exercises. Information Systems Frontiers, 12(1), 49-65. https://doi.org/10.1007/s10796009-9174-z

Bisri, M. B. F. F. (2013). Examining Inter-organizational Network during Emergency Response of West Java Earthquake 2009, Indonesia. Procedia Environmental Sciences, 17, 889-898. https://doi.org/10.1016/j.proenv.2013.02.107

BNPB. (2020a). Jumlah Kasus Covid-19. http://covid19.bnpb.go.id

BNPB. (2020b). UU No. 24 tahun 2007 tentang Penanggulangan Bencana. https://bnpb.go.id/ppid/file/UU_24_2007.pdf

Borgatti, S. P., \& Li, X. (2009). On social network analysis in a supply chain context. Journal of Supply Chain Management, 45(2), 5-22. https://doi.org/10.1111/j.1745493X.2009.03166.x

Borgatti, S. P., \& Ofem, B. (2010). The ties of change: Social Network Theory and Application in Education. In Overview: Social network theory and analysis (pp. 17-29).

Centre for Research on the Epidemiology of Disasters - CRED. (2020). Disaster Classification. CRED-Belgium. https://www.emdat.be/explanatory-notes

Chatfield, A., \& Brajawidagda, U. (2012). Twitter Tsunami Early Warning Network: a Social Network Analysis of Twitter Information Flow. Proceedings of the 23rd Australasian Conference on Information Systems 2012, 1-10. http://ro.uow.edu.au/eispapers/136 
Creswick, N., Westbrook, J. I., \& Braithwaite, J. (2009). Understanding communication networks in the emergency department. BMC Health Services Research, 9, 1-9. https://doi.org/10.1186/1472-6963-9-247

Cross, R., Borgatti, S. P., \& Parker, A. (2002). Strategic Collaboration: Using Social Network Analysis to Integrate Human Networks. California Management Review, 44(2).

Department of Health, P. (2020). Covid-19 Inter-Agency Task Force for the Management of Emerging Infectious Diseases Resolutions. https://www.doh.gov.ph/COVID-19/IATFResolutions

Djalante, R., Lassa, J., Setiamarga, D., Mahfud, C., Sudjatma, A., Indrawan, M., Haryanto, B., Sinapoy, M. S., Rafliana, I., Djalante, S., Gunawan, L. A., Anindito, R., Warsilah, H., \& Surtiari, I. G. A. (2020). Review and analysis of current responses to COVID-19 in Indonesia: Period of January to March 2020. Progress in Disaster Science, 100091. https://doi.org/10.1016/j.pdisas.2020.100091

Drabek, T. E. (2005). Theories relevant to emergency management versus a theory of emergency management. Journal of Emergency Management, 3(4), 49-54.

Drew, R., Aggleton, P., Chalmers, H., \& Wood, K. (2011). Using social network analysis to evaluate a complex policy network. Evaluation, 17(4), 383-394. https://doi.org/10.1177/1356389011421699

EKONID. (2020). COVID-19 developments in Indonesia. EKONID, AHK and DIIH. https://indonesien.ahk.de/en/infocenter/news/news-details/covid-19-developments-inindonesia

Eriyanto. (2014). Analisis Jaringan Komunikasi (Printed). Prenada Media Group.

Forman, R., Atun, R., Mckee, M., \& Mossialos, E. (2020). 12 Lessons learned from the management of the coronavirus pandemic. Health Policy, 10-13.

Franco, Z., Ahmed, S., Kuziemsky, C., Biedrzycki, P., \& Kissack, A. (2013). Using social network analysis to explore issues of latency, connectivity, interoperability \& sustainability in community disaster response. ISCRAM 2013 Conference Proceedings 10th International Conference on Information Systems for Crisis Response and Management, May, 896-900.

Giordano, R., Pagano, A., Pluchinotta, I., del Amo, R. O., Hernandez, S. M., \& Lafuente, E. S. (2017). Modelling the complexity of the network of interactions in flood emergency management: The Lorca flash flood case. Environmental Modelling and Software, 95, 180-195. https://doi.org/10.1016/j.envsoft.2017.06.026

Harapan, H., Itoh, N., Yufika, A., Winardi, W., Keam, S., Te, H., Megawati, D., Hayati, Z., Wagner, A. L., \& Mudatsir, M. (2020). Coronavirus disease 2019 (COVID-19): A literature review. Journal of Infection and Public Health, 13, 667-673. https://doi.org/10.1016/j.jiph.2020.03.019

Harris, J. K., \& Clements, B. (2007). Using social network analysis to understand Missouri's system of public health emergency planners. Public Health Reports, 122(4), 488-498. https://doi.org/10.1177/003335490712200410

Hether, H. J., Murphy, S. T., \& Valente, T. W. (2016). A social network analysis of supportive interactions on prenatal sites. Digital Health, 2(0), 205520761662870. https://doi.org/10.1177/2055207616628700

Holmes, B. J. (2008). Communicating about emerging infectious disease: The importance of research. Health, Risk and Society, 10(4), 349-360. https://doi.org/10.1080/13698570802166431

Hossain, L., \& Kuti, M. (2010). Disaster response preparedness coordination through social networks. Disasters, 34(3), 755-786. https://doi.org/10.1111/j.1467-7717.2010.01168.x

Houghton, R. J., Baber, C., McMaster, R., Stanton, N. A., Salmon, P., Stewart, R., \& Walker, G. (2006). Command and control in emergency services operations: A social network 
analysis. Ergonomics, 49(12-13), 1204-1225.

https://doi.org/10.1080/00140130600619528

Indonesian Ministry of Foreign Affairs. (2020). Additional Measures of The Indonesian

Government in Relation to COVID-19 Response.

https://kemlu.go.id/osaka/en/news/5662/additional-measures-of-the-indonesian-

government-in-relation-to-covid-19-response

Jacomy, M., Venturini, T., Heymann, S., \& Bastian, M. (2014). ForceAtlas2, a continuous graph layout algorithm for handy network visualization designed for the Gephi software. PLoS ONE, 9(6), 1-12. https://doi.org/10.1371/journal.pone.0098679

Jee, Y. (2020). WHO International Health Regulations Emergency Committee for the COVID-19 outbreak. In Epidemiology and health. https://doi.org/10.4178/epih.e2020013

Kapucu, N. (2015). Introduction Social Network Analysis Applications in Complex Governance Networks. Complexity, Governance \& Networks, 02(1), 1-4. https://doi.org/10.7564/15-cgn29

Kapucu, N., Yuldashev, F., \& Feldheim, M. A. (2011). Nonprofit Organizations in Disaster Response and Management: A Network Analysis. European Journal of Economic and Political Studies, 4(1), 83-112. https://doi.org/10.1991/jefa.v2i1.a13

Kim, S. J., Han, J. A., Lee, T. Y., Hwang, T. Y., Kwon, K. S., Park, K. S., Lee, K. J., Kim, M. S., \& Lee, S. Y. (2014). Community-based risk communication survey: Risk prevention behaviors in communities during the H1N1 crisis, 2010. Osong Public Health and Research Perspectives, 5(1), 9-19. https://doi.org/10.1016/j.phrp.2013.12.001

Lee, S. T., \& Basnyat, I. (2013). From Press Release to News: Mapping the Framing of the 2009 H1N1 A Influenza Pandemic. Health Communication, 28(2), 119-132. https://doi.org/10.1080/10410236.2012.658550

Lindell, M. K., Perry, R. W., \& Prater, C. S. (2005). Organizing Response to Disasters with the Incident Command System / Incident Management System ( ICS / IMS ).

International Workshop on Emergency Response and Rescue, October 31-November 1, 2005.

Longstaff, P. H., \& Yang, S. U. (2008). Communication management and trust: Their role in building resilience to "surprises" such as natural disasters, pandemic flu, and terrorism. Ecology and Society, 13(1). https://doi.org/10.5751/ES-02232-130103

Lurie, N., Manolio, T., Patterson, A. P., Collins, F., \& Frieden, T. (2013). Research as a part of public health emergency response. New England Journal of Medicine, 368(13), 1251-1255. https://doi.org/10.1056/NEJMsb1209510

Lyu, S. Y., Chen, R. Y., Wang, S. fan S., Weng, Y. L., Peng, E. Y. C., \& Lee, M. B. (2013). Perception of spokespersons' performance and characteristics in crisis communication: Experience of the 2003 severe acute respiratory syndrome outbreak in taiwan. Journal of the Formosan Medical Association, 112(10), 600-607.

https://doi.org/10.1016/j.jfma.2012.12.005

Magsino, S. L. (2009). Applications of Social Network Analysis for Building Community Disaster Resilience. In Applications of Social Network Analysis for Building Community Disaster Resilience. https://doi.org/10.17226/12706

Mietzner, M. (2012). Indonesia's democratic stagnation: Anti-reformist elites and resilient civil society. Democratization, 19(2), 209-229. https://doi.org/10.1080/13510347.2011.572620

Ministry of Health Japan. (2020). Basic Policies for Novel Coronavirus Disease Control. https://translation.mhlw.go.jp/LUCMHLW/ns/tl.cgi/https://www.mhlw.go.jp/stf/seisaku nitsuite/bunya/newpage_00032.html?SLANG=ja\&TLANG $=$ en\&XMODE $=0 \& X C H A R$ 


\section{SET $=$ utf- $8 \&$ XJSID $=0$}

Mohammadfam, I., Bastani, S., Esaghi, M., Golmohamadi, R., \& Saee, A. (2015). Evaluation of coordination of emergency response team through the social network analysis. Case study: Oil and gas refinery. Safety and Health at Work, 6(1), 30-34.

https://doi.org/10.1016/j.shaw.2014.09.004

Nerlich, B., \& Halliday, C. (2007). Avian flu: The creation of expectations in the interplay between science and the media. In Sociology of Health and Illness (Vol. 29, Issue 1, pp. 46-65). https://doi.org/10.1111/j.1467-9566.2007.00517.x

Olanrewaju, A. T., \& Ahmad, R. (2018). Examining the Information Dissemination Process on Social Media During the Malaysia 2014 Floods Using Social Network Analysis (SNA). Journal of Information and Communication Technology (JICT), 17(1), 141-166.

Patterson, P. D., Pfeiffer, A. J., Weaver, M. D., Krackhardt, D., Arnold, R. M., Yealy, D. M., \& Lave, J. R. (2013). Network analysis of team communication in a busy emergency department. BMC Health Services Research, 13(1). https://doi.org/10.1186/1472-696313-109

Pratama, A. B. (2017). Bureaucracy Reform Deficit in Indonesia: A Cultural Theory Perspective. Journal of Public Administration and Governance, 7(3), 88. https://doi.org/10.5296/jpag.v7i3.11519

Raju, E., \& Van Niekerk, D. (2013). Intra-governmental coordination for sustainable disaster recovery: A case-study of the Eden District Municipality, South Africa. International Journal of Disaster Risk Reduction, 4, 92-99. https://doi.org/10.1016/j.ijdrr.2013.03.001

Reintjes, R., Das, E., Klemm, C., Richardus, J. H., Keßler, V., \& Ahmad, A. (2016). "Pandemic public health paradox": Time series analysis of the 2009/10 influenza $\mathrm{A} / \mathrm{H} 1 \mathrm{~N} 1$ epidemiology, media attention, risk perception and public reactions in 5 European countries. PLoS ONE, 11(3), 1-14. https://doi.org/10.1371/journal.pone.0151258

Rice, E., \& Yoshioka-Maxwell, A. (2015). Social network analysis as a toolkit for the science of social work. Journal of the Society for Social Work and Research, 6(3), 369-383. https://doi.org/10.1086/682723

Rosser, A., Wilson, I., \& Sulistiyanto, P. (2011). Leaders, Elites and Coalitions: The Politics of Free Public Services in Decentralised Indonesia. May.

Scanlon, J., McMahon, T., \& Van Haastert, C. (2007). Handling mass death by integrating the management of disasters and pandemics: Lessons from the Indian ocean tsunami, the Spanish flu and other incidents. Journal of Contingencies and Crisis Management, 15(2), 80-94. https://doi.org/10.1111/j.1468-5973.2007.00511.x

Sellnow, T., Parrish, A., \& Semenas, L. (2019). From Hoax as Crisis to Crisis as Hoax: Fake News and Information Disorder as Disruptions to the Discourse of Renewal. Journal of International Crisis and Risk Communication Research, 2(1), 121-142. https://doi.org/10.30658/jicrcr.2.1.6

Silva, N. T. C. da, Fra.Paleo, U., \& Ferreira Neto, J. A. (2019). Conflicting Discourses on Wildfire Risk and the Role of Local Media in the Amazonian and Temperate Forests. International Journal of Disaster Risk Science, 10(4), 529-543. https://doi.org/10.1007/s13753-019-00243-z

Tempo. (2020). TEMPO Magazine. Tempo. https://majalah.tempo.co/gallery

Thangaraj, M., \& Amutha, S. (2018). Mgephi : Modified Gephi for Effective Social Network Analysis. International Journal of Scientific Research in Computer Science, Engineering and Information Technology, 1(1), 39-50.

Uhr, C., \& Johansson, H. (2007). Mapping an emergency management network. International Journal of Emergency Management, 4(1), 104-118. https://doi.org/10.1504/IJEM.2007.012392 
Van der Hulst, R. C. (2009). Introduction to Social Network Analysis (SNA) as an investigative tool. Trends in Organized Crime, 12(2), 101-121. https://doi.org/10.1007/s 12117-008-9057-6

Vasterman, P. L. M., \& Ruigrok, N. (2013). Pandemic alarm in the Dutch media: Media coverage of the 2009 influenza A (H1N1) pandemic and the role of the expert sources. European Journal of Communication, 28(4), 436-453. https://doi.org/10.1177/0267323113486235

Vaughan, E., \& Tinker, T. (2009). Effective health risk communication about pandemic influenza for vulnerable populations. American Journal of Public Health, 99(SUPPL. 2). https://doi.org/10.2105/AJPH.2009.162537

Vedula, N., Parthasarathy, S., \& Shalin, V. L. (2017). Predicting trust relations within a social network: A case study on emergency response. WebSci 2017 - Proceedings of the 2017 ACM Web Science Conference, 53-62. https://doi.org/10.1145/3091478.3091494

Wachinger, G., Renn, O., Begg, C., \& Kuhlicke, C. (2013). The risk perception paradoximplications for governance and communication of natural hazards. Risk Analysis, 33(66), 1049-1065. https://doi.org/10.1111/j.1539-6924.2012.01942.x

Wahyuni, N. C. (2020). Indonesia Currently Has Highest Covid-19 Mortality Rate in Asia. https://jakartaglobe.id/news/indonesia-currently-has-highest-covid19-mortality-rate-inasia

WHO. (2013). A Systematic Review of Public Health Emergency Operations Centres (EOC) (Issue December).

WHO. (2019). Emergency Response Framework. WHO; WHO. https://www.who.int/hac/about/erf/en/

WHO. (2020). Global update on coronavirus disease. https://www.who.int/indonesia/news/novel-coronavirus

World Health Organization. (2020). Critical preparedness, readiness and response actions for COVID-19. WHO.

$\mathrm{Xu}, \mathrm{K} .$, \& Zhao, L. (2011). Individual swift trust and cooperation in emergency rescue team members. IET Conference Publications. https://doi.org/10.1049/cp.2011.0324

Yeo, J., Knox, C. C., \& Jung, K. (2018). Unveiling cultures in emergency response communication networks on social media: following the 2016 Louisiana floods. Quality and Quantity, 52(2), 519-535. https://doi.org/10.1007/s11135-017-0595-3 